Original Article

\title{
The effect of parity on pelvic floor muscle strength and quality of life in women with urinary incontinence: a cross sectional study
}

\author{
ÖZlem Çinar Özdemir, PT, PhD ${ }^{1 *}$, Yesim Bakar, PT, PhD ${ }^{1)}$, Nuriye ÖZengin, PT, PhD ${ }^{1)}$, \\ Bülent Duran, $\mathrm{MD}^{2)}$ \\ 1) School of Physical Therapy and Rehabilitation, Abant Izzet Baysal University: 14280 Bolu, Turkey \\ 2) Department of Obstetrics and Gynecology, Faculty of Medicine, Abant Izzet Baysal University, Turkey
}

\begin{abstract}
Purpose] The purpose of this study was to analyze the pelvic floor muscle (PFM) activity after vaginal birth, and the effect of parity on PFM strength and quality of life (QoL) in women with urinary incontinence. [Subjects and Methods] Patients ( $\mathrm{n}=241$ ) who gave birth vaginally and experienced urinary incontinence were divided into three groups: group 1 consisted of women having 1-3 children, group 2 consisted of women having 4-6 children, and group 3 consisted of women having more than 6 children. All patients underwent detailed examination of the PFM. The Turkish version of the self-administered Incontinence Quality of Life Instrument (I-QoL) questionnaire was used to evaluate the effects of stress urinary incontinence on participants' QoL. [Results] Comparison of PFM strengths showed a significant intergroup difference. Group 1 showed significantly higher PFM strength scores than those of groups 2 and 3. I-QoL scores related to stress incontinence showed a significant intergroup difference. As number of deliveries increased, quality of life decreased. Comparison of PFM strengths and I-QoL scores related to stress incontinence showed a significant intergroup difference. [Conclusion] Increasing the awareness of PFM training in women will reduce potential postpartum incontinence due to a weak PFM strength; and will increase quality of life.

Key words: Parity, Pelvic floor muscle strength, Urinary incontinence
\end{abstract}

(This article was submitted Feb. 13, 2015, and was accepted Apr. 1, 2015)

\section{INTRODUCTION}

The pelvic floor muscles (PFMs) have an important role in pelvic organ support and the continence control system ${ }^{1)}$. Different stages in a woman's life, such as pregnancy, postpartum period, and menopause, can cause changes in these muscles ${ }^{2)}$. Damage to the pelvic floor can result in incontinence and constipation, decreased or total loss of PFM strength, or genital prolapse. These conditions negatively affect quality of life (QoL). Pregnancy and vaginal delivery are major risk factors for weakened PFMs, which can cause stress urinary incontinence (SUI) and pelvic organ prolapse in younger women. These can have negative consequences on sexual, physical, and professional activities ${ }^{3)}$.

Pregnancy-related hormonal and mechanical factors can expose women to increased risk of SUI, thus worsening urinary urgency, and increasing micturition ${ }^{4)}$. These conditions are believed to be caused by damaged fascias, ligaments, peripheral nerves, and muscles that function in pelvic organ

*Corresponding author. Özlem Çınar Özdemır (E-mail: ozlemcinar314@hotmail.com)

(C2015 The Society of Physical Therapy Science. Published by IPEC Inc. This is an open-access article distributed under the terms of the Creative Commons Attribution Non-Commercial No Derivatives (by-ncnd) License $<$ http://creativecommons.org/licenses/by-nc-nd/3.0/>. support and continence control ${ }^{5)}$. Furthermore, pelvic floor dysfunction can be affected by age, genetic factors, estrogen levels, and increased body weight ${ }^{6}$ ).

Middle-aged women after one single vaginal birth have approximate increases of $12 \%$ and $8 \%$ in the prevalence of urinary incontinence and symptomatic pelvic organ prolapse, respectively, compared with those with delivery by one caesarean section ${ }^{7)}$. Postpartum MRI studies in one-para women have revealed levator ani muscle injury in 6-10\% of women after spontaneous vaginal delivery, in $17-33 \%$ of women after vacuum extraction, and in $67-71 \%$ of women after forceps delivery, but this injury was not identified in nulliparous women or after caesarean section ${ }^{7}$.

Measurement of PFM strength is an important parameter for PFM training. Various methods such as magnetic resonance imaging, perineometry, anal endosonography, translabial ultrasound, manometry, electromyography, digital vaginal palpation, and neurophysiological and urodynamic studies of the pelvic floor are used to evaluate the PFMs and to diagnose genitourinary and anal tract disorders $3,8,9$ ).

Most common methods include perineometry and digital vaginal palpation to measure PFM strength ${ }^{8)}$. Pressure perineometry, which is a simple manometric device to measure intravaginal pressure, was introduced by Kegel in 1948 ${ }^{10)}$. It is a reliable quantitative method to measure intravaginal pressure and is widely used in clinical research. The technique has strong reproducibility ${ }^{11)}$. It has been shown that 
the measurement of intravaginal pressure only reliably depicts the pressure rise caused by a PFM contraction in combination with an inward movement of the perineum. However there are limited data on vaginal birth, urinary incontinence, QoL, and perineometry measurement in the study of PFM strength, and there is limited literature on the effects of parity on PFM strength. The aim of this study was to test PFM activity after vaginal birth, and to analyze the effect of parity on PFM strength and QoL in women with urinary incontinence.

\section{SUBJECTS AND METHODS}

This study included 241 women who gave birth to all their children vaginally and experienced urinary incontinence from December 2012 to June 2013. Patients were diagnosed according to their detailed histories and, clinical and physical examinations by a gynecologist. The patients were divided into three groups: group $1(n=132)$ consisted of women having 1-3 children, group $2(n=88)$ consisted of women having 4-6 children, and group $3(n=21)$ consisted of women having more than 6 children. The study was approved by the Ethical Research Committee of the Faculty of Medicine, Abant Izzet Baysal University. The participants were informed about the study and provided informed consent.

The women who participated in this study were recruited from the Department of Obstetrics and Gynecology, Faculty of Medicine, Abant Izzet Baysal University, Bolu in Turkey. The inclusion criteria for participation in this study were normal contraction of the PFMs, which was evaluated by vaginal palpation, urinary incontinence postpartum, and primipara or multipara. The exclusion criteria were pregnancy; work as a manual laborer; systemic disease such as hypertension, diabetes mellitus, obesity, or chronic cough; and history of pelvic surgery or pelvic prolapse.

Some physical and demographic characteristics of the patients were recorded, including body mass index, height, weight, medical history, job status, educational level, gravidity, abortus, parity, dilatation and curettage, type of delivery, and presence of episiotomy and/or perineal tears. Job status was classified as worker, housewife or retired. Education level was classified according to the Turkish education system.

The patients underwent detailed examination of the PFMs. The examination included perineometry on one occasion only. The evaluations were conducted by an experienced physiotherapist who was unaware of the subject group of the study.

PFM strength was evaluated according to pressure change in the vagina, which was measured via a cavity probe (Myomed 932; Enraf-Nonius, Delft, Netherlands). The device was adjusted to perineometry mode, and it allows for the reproduction of pressure signals at an adjustable sensibility and time scale. Vaginal resting pressure can be shown on an LCD screen after insertion of the probe into the vagina. The tip of the probe is covered with a silicone ring to control depth of insertion, and the duration of each contraction can be precisely measured by means of lines displayed on the screen, which can be moved to capture the actual parameter. The device provides results in centimeters of water $\left(\mathrm{cm} \mathrm{H}_{2} \mathrm{O}\right)$ for pressure measurements. Reliability testing of the device showed intra-observer reliability, with an intraclass correlation coefficient (ICC) of $0.97^{12}$ ). Prior to the procedure, the participants were informed about how to contract the PFMs. They were asked to lie in a standardized supine crook lying position and requested to produce the maximum number of voluntary PFM contractions without pelvic movement or visible movement of hip, gluteal, or abdominal muscles ${ }^{13)}$. Palpation and observation were used as the basis of correct contraction, which was defined as an inward movement involving squeezing the floor openings. After teaching the women how to contract the PFMs, they were asked to perform maximal voluntary contraction with three repetitions and to maintain each contraction for $10 \mathrm{sec}-$ onds. The mean scores of these three contractions were used.

The Turkish version of the self-administered Incontinence Quality of Life Instrument (I-QoL) questionnaire was used to evaluate the effects of SUI on participants' QoL. The instrument consists of a 4-item scale used to evaluate the degree of difficulty, comprising $0=$ not at all, $1=$ slightly, $2=$ moderately, and $3=$ greatly. Possible scores ranged between 0 and 84 , representing 28 questions scored as $0-3$. The sum of the scores was recorded for analysis ${ }^{14)}$.

The PASW Statistics software (version 18.0, demo, SPSS Inc., Chicago, IL, USA) was used for statistical analysis. Quantitative data are presented as the mean and standard deviation, while qualitative data are presented in percentage frequency (n \%). One-way ANOVA was used to analyze the results. The Tukey test was used to determine the category that causes the difference. P-values less than 0.05 were considered statistically significant.

\section{RESULTS}

A total of 241 participants completed the measurements, and 8 were excluded from the study. Of these 8 women, 4 withdrew from the study because they could not contract their PFMs and 4 were excluded because they had not given birth to any children. Therefore the statistic analysis was performed with data from 233 participants. The mean age of the participants was $47.5 \pm 9.0$ years in group $1(\mathrm{n}=128)$, $55.2 \pm 9.3$ years in group $2(\mathrm{n}=84)$, and $51.9 \pm 22.2$ years in group $3(\mathrm{n}=21)$. Tables 1 and 2 indicate some general and sociodemographic characteristics of the patients.

Comparison of PFM strength showed a significant intergroup difference $(p=0.002)$. The Tukey test indicated that the difference was caused by Group 1, which showed significantly higher PFM strength scores than groups 2 and 3 (Table 3). I-QoL scores related to stress incontinence showed a significant intergroup difference $(\mathrm{p}=0.001)$. The mean I-QoL values of groups 1,2 , and 3 were $31.5 \pm 22.5$, $36.7 \pm 25.3$, and $51.9 \pm 22.2$, respectively. As number of deliveries increased, quality of life decreased.

\section{DISCUSSION}

Urinary incontinence problems increase in parallel with the number of deliveries. The literature includes studies of symptoms related to perineal muscle strength and urinary 
Table 1. Sociodemographic characteristics of the study population $(n=233)$

\begin{tabular}{|c|c|c|c|c|c|c|c|}
\hline & & \multicolumn{2}{|c|}{$\begin{array}{c}\text { Group } 1 \\
\mathrm{n}=128\end{array}$} & \multicolumn{2}{|c|}{$\begin{array}{c}\text { Group } 2 \\
n=84\end{array}$} & \multicolumn{2}{|c|}{$\begin{array}{c}\text { Group } 3 \\
n=21\end{array}$} \\
\hline & & $\mathrm{n}$ & $\%$ & $\mathrm{n}$ & $\%$ & $\mathrm{n}$ & $\%$ \\
\hline \multirow[t]{5}{*}{ Educational Status } & Illiterate & 8 & 6.2 & 16 & 19 & 7 & 33.3 \\
\hline & Literate & 3 & 2.3 & 8 & 9.5 & 1 & 4.8 \\
\hline & Primary level & 89 & 69.5 & 58 & 69 & 13 & 61.9 \\
\hline & High school level & 12 & 9.4 & - & - & - & - \\
\hline & University & 16 & 12.5 & 2 & 2.4 & - & - \\
\hline \multirow[t]{3}{*}{ Occupation } & Housewife & 97 & 75.8 & 75 & 89.3 & 21 & 100 \\
\hline & Worker & 14 & 10.9 & 5 & 6 & - & - \\
\hline & Retired & 17 & 13.3 & 4 & 4.7 & - & - \\
\hline \multirow[t]{3}{*}{ Menopausal state } & Premenopausal & 36 & 28.1 & 16 & 19 & 2 & 9.5 \\
\hline & Normal & 42 & 32.8 & 9 & 10.7 & 4 & 19 \\
\hline & Postmenopausal & 50 & 39.1 & 59 & 70.2 & 15 & 71.4 \\
\hline
\end{tabular}

Table 2. Demographic and clinical features of the patients

\begin{tabular}{lccc}
\hline & $\begin{array}{c}\text { Group 1 } \\
\mathrm{n}=128\end{array}$ & $\begin{array}{c}\text { Group 2 } \\
\mathrm{n}=84\end{array}$ & $\begin{array}{c}\text { Group 3 } \\
\mathrm{n}=21\end{array}$ \\
& $\mathrm{X} \pm \mathrm{SD}$ & $\mathrm{X} \pm \mathrm{SD}$ & $\mathrm{X} \pm \mathrm{SD}$ \\
\hline Age (years) & $47.5 \pm 9.0^{*}$ & $55.2 \pm 9.3$ & $51.9 \pm 22.2$ \\
Height $(\mathrm{m})$ & $1.58 \pm 0.05$ & $1.5 \pm 0.0$ & $1.57 \pm 0.07$ \\
Weight $(\mathrm{kg})$ & $76.0 \pm 13.2$ & $79.1 \pm 14.5$ & $80.5 \pm 14.8$ \\
BMI $\left(\mathrm{kg} / \mathrm{m}^{2}\right)$ & $30.4 \pm 5.3$ & $32.2 \pm 6.1$ & $33.0 \pm 6.3$ \\
\hline
\end{tabular}

*Signicant difference $(\mathrm{p}<0.05)$

incontinence ${ }^{2-4)}$. However, these studies included women who had a maximum 2 deliveries $^{7-15)}$. There is a limited research on PFM strength among women who have had 2 or more deliveries. This study analyzed PFM strength and QoL criteria among multipara women. It was found that women who had 1-3 deliveries had the highest PFM strength; and that PFM strength decreased as the number of deliveries increased.

Bo et al. ${ }^{16)}$ concluded that vaginal palpation was not a valid method to measure PFM strength. Although the International Continence Society (ICS) ${ }^{17)}$; validated the use of a perineometer to evaluate PFM strength, it is difficult to achieve consistency in results because a wide variety of devices of varying sizes and units have been used in the literature ${ }^{18)}$. Marshall et al. ${ }^{19)}$ used digital palpation, perineometry, and electromyography and compared PFM strength in nulliparous and primiparous women. The procedure was carried out ten months after vaginal delivery, and it was observed that nulliparous women had significantly higher PFM strengths.

It is reported in the literature that PFMs weaken after delivery, and that normal delivery is the most important factor in damage to the PFMs. Most previous studies show that PFM strength decreases after the first vaginal delivery ${ }^{7}$. Kim et al. ${ }^{20)}$ concluded that pelvic floor muscle contractions induce significantly different vaginal pressures between subjects with nulliparous and vaginal delivery histories, but no significant difference in vaginal pressure was induced between their vaginal delivery group and cesarean delivery
Table 3. Comparison of quality of life and pelvic floor muscle strength among groups

\begin{tabular}{lccc}
\hline & Group 1 & Group 2 & Group 3 \\
& $\mathrm{n}=128$ & $\mathrm{n}=84$ & $\mathrm{n}=21$ \\
& $\mathrm{X} \pm \mathrm{SD}$ & $\mathrm{X} \pm \mathrm{SD}$ & $\mathrm{X} \pm \mathrm{SD}$ \\
\hline Perineometry $\left(\mathrm{cm} \mathrm{H}_{2} \mathrm{O}\right)$ & $25.5 \pm 14.6 *$ & $19.1 \pm 12.3$ & $19.6 \pm 12.9$ \\
I-QoL & $31.5 \pm 22.5$ & $36.7 \pm 25.3$ & $51.9 \pm 22.2 *$ \\
\hline *Signicant difference $(\mathrm{p}<0.05$ one-way ANOVA) &
\end{tabular}

group. In the present study, we compared the PFM strength in women who had 1-3, 4-6, and more than 6 deliveries. The highest PFM strength was found in women who had 1-3 deliveries, and the PFM strength decreased as the number of deliveries increased. However, it was observed that there was no difference in PFM strengths between women who had 4-6 deliveries and those who had more than 6 deliveries. It is believed that this was the results of the smaller number of women who had more than 6 deliveries than those who had 4-6 deliveries. Bahl et al. ${ }^{21)}$ analyzed pelvic floor morbidity in 283 women three years after instrumental delivery and cesarean delivery in the second stage of labor. They reported that pelvic floor symptoms were not worsened by a subsequent delivery. However, Faltin et al. ${ }^{22)}$ analyzed 100 women at 3 and 30 months after their first delivery and reported that subsequent deliveries increase the risk of anal incontinence, especially in women with a sphincter defect after their first delivery. Kim et al. ${ }^{23)}$ found significant differences between their nulliparous group and vaginal delivery group; and between their nulliparous group and Cesarean delivery group, and their results suggest that child birth delivery method changes the vaginal pressure. Peschers et al. ${ }^{24)}$ used palpation, perineometry, and perineal ultrasound 3-8 days after delivery to evaluate PFM strength values of primiparous and multiparous women who had vaginal deliveries. Their study showed that PFM strength decreased significantly after vaginal delivery; however, PFM subsequently increased 6-10 weeks after delivery. There was no significant difference in PFM strength at 6-10 weeks postpartum compared with 9-15 months postpartum. In another 
study, PFM strength was evaluated during early postpartum (3-6 months $)^{25)}$. However, in Turkey, the concept of gynecological rehabilitation is quite new, and thus we were unable to evaluate the women in our study immediately after normal delivery. Furthermore, our study was limited by patients' avoidance of gynecological examination, which prevented us from evaluating the women at an early stage.

The causes of SUI following pregnancy and delivery, especially long-term cases, are still not fully understood. Hormonal changes or autonomic denervation during pregnancy might play a role. On the other hand, damage to muscle, nerve, or connective tissue in the lower urinary tract and pelvic floor are associated with vaginal delivery ${ }^{26)}$. The literature contains a limited portion of prospective long-term research with objective findings. It was reported that levator ani muscle abnormality was more common 9-12 months after the first delivery in women with urinary incontinence when compared with continent primiparous women. The abnormality was much more common in nulliparous women ${ }^{27)}$.

We believe that the most important cause of weak PFM strength in the women included in this study was that none of the women took part in PFM strength training following delivery; they were not informed about strengthening the PFM, and thus were at greater risk of developing urinary incontinence.

Urinary and anal incontinence symptoms are believed to increase with the first delivery. Previous research shows that urinary incontinence has negative effects on $\mathrm{QoL}^{28)}$, as it effects in psychological, physical, social, personal, and sexual relationships. Robinson et al. ${ }^{29)}$ reported that a questionnaire format can reliably be used to evaluate the complaints of women with urinary incontinence.

In this study, we found that QoL decreased in women with urinary incontinence after normal delivery. There was a difference between the women who had 1-3 deliveries, 4-6 deliveries, and more than 6 deliveries. We found that QoL among women who had more than 6 deliveries was lower than for women in other groups. The findings indicate that as number of deliveries increased, the incontinence-related QoL of the women who had normal delivery decreased as well.

Dimp et al. $^{30)}$ reported that the PFMs underwent histomorphological changes due to vaginal delivery. The present study suggests that all women should attend programs for PFM exercises after vaginal delivery, whether or not they have urinary incontinence. The ICS recommends that women who have vaginal delivery for the first time should attend a PFM strength program to reduce the possibility of developing urinary incontinence after delivery ${ }^{31)}$.

Number of deliveries has been observed to increase in association with low educational level in Turkey, particularly in rural regions ${ }^{32)}$. The concept of urogynecological rehabilitation is quite new in Turkey. Physiotherapists working in the field of women's health and gynecologists believe that raising awareness among women of PFM training will reduce potential postpartum incontinence due to weak PFM strength, and will increase QoL. Considering that the number of deliveries is high in Turkey, we believe that it is important to provide family planning training in health centers; thus, maintaining the number of deliveries at an optimal level might have a positive impact on PFM strength. In addition, family visits should be intensified, and families should be informed about methods of contraception.

\section{REFERENCES}

1) Ashton-Miller JA, Howard D, DeLancey JO: The functional anatomy of the female pelvic floor and stress continence control system. Scand J Urol Nephrol Suppl, 2001, 207: 1-7, discussion 106-125. [Medline] [CrossRef]

2) Amaro JL, Moreira EC, De Oliveira Orsi Gameiro M, et al.: Pelvic floor muscle evaluation in incontinent patients. Int Urogynecol J Pelvic Floor Dysfunct, 2005, 16: 352-354. [Medline] [CrossRef]

3) Riesco ML, Caroci AS, de Oliveira SM, et al.: Perineal muscle strength during pregnancy and postpartum: the correlation between perineometry and digital vaginal palpation. Rev Lat Am Enfermagem, 2010, 18: 11381144. [Medline] [CrossRef]

4) Mørkved S, Bø K: Prevalence of urinary incontinence during pregnancy and postpartum. J Pelvic Floor Dysfunc, 1999, 10: 394-398. [CrossRef]

5) Allen RE, Hosker GL, Smith AR, et al.: Pelvic floor damage and childbirth: a neurophysiological study. Br J Obstet Gynaecol, 1990, 97: 770779. [Medline] [CrossRef]

6) Aukee P, Tihtonen K: [Pregnancy, delivery and pelvic floor disorders]. Duodecim, 2010, 126: 2381-2386. [Medline]

7) Hilde G, Stær-Jensen J, Siafarikas F, et al.: Impact of childbirth and mode of delivery on vaginal resting pressure and on pelvic floor muscle strength and endurance. Am J Obstet Gynecol, 2013, 208: 50.e1-50.e7 [CrossRef]. [Medline]

8) de Oliveira C, Lopes MA, Carla Longo e Pereira L, et al.: Effects of pelvic floor muscle training during pregnancy. Clinics (Sao Paulo), 2007, 62: 439-446. [Medline] [CrossRef]

9) Fitzpatrick M, O'Herlihy C: The effects of labour and delivery on the pelvic floor. Best Pract Res Clin Obstet Gynaecol, 2001, 15: 63-79. [Medline] [CrossRef]

10) Levitt EE, Konovsky M, Freese MP, et al.: Intravaginal pressure assessed by the Kegel perineometer. Arch Sex Behav, 1979, 8: 425-430. [Medline] [CrossRef]

11) Peschers UM, Gingelmaier A, Jundt K, et al.: Evaluation of pelvic floor muscle strength using four different techniques. Int Urogynecol J Pelvic Floor Dysfunct, 2001, 12: 27-30. [Medline] [CrossRef]

12) Sigurdardottir $T$, Steingrimsdottir $T$, Arnason A, et al.: Test-retest intrarater reliability of vaginal measurement of pelvic floor muscle strength using Myomed 932. Acta Obstet Gynecol Scand, 2009, 88: 939-943 [CrossRef]. [Medline]

13) Bø K, Kvarstein B, Hagen RH, et al.: Pelvic floor muscle exercise for the treatment of female stress urinary incontinence: I. reliability of vaginal pressure measurements of pelvic floor muscle strength. Neurourol Urodyn, 1990, 9: 471-477. [CrossRef]

14) Bakar Y, Cinar Özdemir O, Ozengin N, et al.: The use of extracorporeal magnetic innervation for the treatment of stress urinary incontinence in older women: a pilot study. Arch Gynecol Obstet, 2011, 284: 1163-1168 [CrossRef]. [Medline]

15) Gameiro MO, Sousa VO, Gameiro LF, et al.: Comparison of pelvic floor muscle strength evaluations in nulliparous and primiparous women: a prospective study. Clinics (Sao Paulo), 2011, 66: 1389-1394. [Medline]

16) Bø K, Finckenhagen HB: Vaginal palpation of pelvic floor muscle strength: inter-test reproducibility and comparison between palpation and vaginal squeeze pressure. Acta Obstet Gynecol Scand, 2001, 80: 883-887. [Medline] [CrossRef]

17) Messelink B, Benson T, Berghmans B, et al.: Standardization of terminology of pelvic floor muscle function and dysfunction: report from the pelvic floor clinical assessment group of the International Continence Society. Neurourol Urodyn, 2005, 24: 374-380. [Medline] [CrossRef]

18) Barbosa PB, Franco MM, Souza FO, et al.: Comparison between measurements obtained with three different perineometers. Clinics (Sao Paulo), 2009, 64: 527-533. [Medline] [CrossRef]

19) Marshall K, Walsh DM, Baxter GD: The effect of a first vaginal delivery on the integrity of the pelvic floor musculature. Clin Rehabil, 2002, 16: 795-799. [Medline] [CrossRef]

20) Kim H, Shim J, Kim B: Analysis of vaginal pressure and abdominal EMG according to delivery method during pelvic floor muscle contraction. J Phys Ther Sci, 2012, 24: 119-121. [CrossRef]

21) Bahl R, Strachan B, Murphy DJ: Pelvic floor morbidity at 3 years after instrumental delivery and cesarean delivery in the second stage of labor and the impact of a subsequent delivery. Am J Obstet Gynecol, 2005, 192: 789-794. [Medline] [CrossRef] 
22) Faltin DL, Sangalli MR, Roche B, et al.: Does a second delivery increase the risk of anal incontinence? BJOG, 2001, 108: 684-688. [Medline]

23) Kim H, Kak HB, Kim B: A comparison of vaginal pressures and abdominal muscle thickness according to childbirth delivery method during the valsalva maneuver. J Phys Ther Sci, 2014, 26: 443-445. [Medline] [CrossRef]

24) Peschers UM, Schaer GN, DeLancey JO, et al.: Levator ani function before and after childbirth. Br J Obstet Gynaecol, 1997, 104: 1004-1008. [Medline] [CrossRef]

25) Mørkved S, Bø K: The effect of post-natal exercises to strengthen the pelvic floor muscles. Acta Obstet Gynecol Scand, 1996, 75: 382-385. [Medline] [CrossRef]

26) Viktrup L, Lose G: The risk of stress incontinence 5 years after first delivery. Am J Obstet Gynecol, 2001, 185: 82-87. [Medline] [CrossRef]

27) DeLancey JO, Kearney R, Chou Q, et al.: The appearance of levator an muscle abnormalities in magnetic resonance images after vaginal delivery.
Obstet Gynecol, 2003, 101: 46-53. [Medline] [CrossRef]

28) Chiverton PA, Wells TJ, Brink CA, et al.: Psychological factors associated with urinary incontinence. Clin Nurse Spec, 1996, 10: 229-233. [Medline] [CrossRef]

29) Robinson D, Pearce KF, Preisser JS, et al.: Relationship between patient reports of urinary incontinence symptoms and quality of life measures. Obstet Gynecol, 1998, 91: 224-228. [Medline] [CrossRef]

30) Dimpfl T, Jaeger C, Mueller-Felber W, et al.: Myogenic changes of the levator ani muscle in premenopausal women: the impact of vaginal delivery and age. Neurourol Urodyn, 1998, 17: 197-205. [Medline] [CrossRef]

31) Smith JH, Berghmans B, Burgio K, et al.: Adult conservative managment. In: Abrams P, Cardozo L, Saad K, Wein A (eds). Incontinence, 2008, 4th International Consultation on Incontinence. Health Publication, Paris, pp $1025-1120$.

32) http://www.tuik.gov.tr/PreHaberBultenleri.do?id=13618. 